\title{
A Re-Interrogation of Immunization Programme in Enugu State Nigeria: Impediments and Way Forward
}

\author{
Professor Emma E.O. Chukwuemeka \\ Department of Public Administration, \\ Nnamdi Azikiwe University, Awka Nigeria \\ E-mail: ee.chukwuemeka@unizik.edu.ng and hrvkonsult@yahoo.com \\ Tel: +2348060967169 \\ Dr. Aloysius Aduma \\ Department of Public Administration \\ Enugu State University of Science and Technology \\ E-mail: aloyaduma@yahoo.com \\ Tel: +2348066069928 \\ Francisca Ogo Ezeigwe \\ Department of Public Administration \\ Federal Polytechnic Oko
}

Received: December 13, 2018 Accepted: June 25, 2019 Published: June 27, 2019

doi:10.5296/jpmr.v5i1.14986 URL: https://doi.org/10.5296/jpmr.v5i1.14986

\begin{abstract}
Immunization is a public health strategy and programme for improving child survival, not only by directly combating key diseases that kill children but also by providing a platform for other health services. Millions of children in low-income areas in Enugu State are believed not to receive the full series of the vaccines on the National routine immunization schedule. The underlying tragedy provokes this research. Random sampling technique was used in choosing six low-income areas in Enugu State. Focus group discussion, questionnaire and face- to- face interview were the major tools used for data collection. Focus group discussion
\end{abstract}


was essentially used to elicit information from mothers who have aversion for immunization. Statistical tools such as frequency tables, correlation coefficient and chi-square were used in data analysis and test of hypotheses. The correlation coefficient test revealed high correlation between lopsidedness in the implementation of immunization policy and high rate of death among children in low-income areas. The chi-square test revealed that immunization policies are properly formulated but most low-income parents do not take their children for full immunization schedule because of insufficient enlightment campaign and sensitization strategy. Essentially, we recommended that immunization certificate should be given to mothers who fully immunized their children. Those who resist immunization should be deprived of democracy dividends from the government.

Keywords: immunization, public policy, children, disease control

\section{Introduction}

The evolution of primary health care services in Nigerian can be traced back to the pre-colonial era. This period argues Eze (2016) comprised the traditional care continuum, which antedated the colonial and post-colonial periods. The national health policy did not happen in a vacuum. In Nigeria, the traditional medical practices in most areas of the country including Enugu State existed long before the contact and subsequent influence of the colonial agents. Examples include; herbalists, traditional birth attendants. Traditional surgeons etc. While these practices in different societies are not in doubt, what might be called to question is whether they were systematic, that is organized. It will be evident in subsequent discussion that even modern health delivery was almost piggy-backed in the national development plans. Health care service argues Chukwuemeka (2009) were initially 'unorganized' and therefore not systematic with reference to public policy. In this report, the early modern health services in Nigerian is characterized as having functioned as an 'iron system'. Public policy generally engenders global directives or framework on the main lines of action to be followed (Dror, 1978). Health care in colonial era spanned the period of colonial rule to 1960, when Nigeria gained political independence. This era was also when the first attempt was made at planning health services development in Nigeria. This effort was also part of exercise, which produced the overall ten-year development plans for welfare from 1946 -1958, covering all aspects of governmental activities in the country (Sorungbe, 1990). In the neo-colonial era (post-colonial) as the period when colonial services became regional medical services after independence i.e. from 1960. Hitherto, the health care policies in Nigeria bordered on three levels of care namely: primary (base) health care (BHC), secondary health care and tertiary health care. The expanded program on immunization (EPI) was first launched in Nigeria in 1978 and re-launched in 1984. The $27^{\text {th }}$ World Assembly (WHA) recognized the need and potential for control through a well-coordinated immunization program. The Assembly therefore recommend in its resolution WHA 27, 57, that an integrated program on immunization be developed by member states. Diseases to be covered include measles, diphtheria, pertussis, tetanus, polio, tuberculosis and small pox depending on local epidemic conditions. Prior to 1975, immunization efforts in Nigeria were directed against only small pox and measles. But following the resolution in the $27^{\text {th }}$ WHA, the government emphasized EPI in $4^{\text {th }}$ National Development plan (Uwakwe, 2017). The 
diseases covered were then expanded to include tetanus, polio, pertussis, diphtheria and tuberculosis. In 1976, National EPI pilot program was started in former western region. By 1977, all the states were running pilot program. In 1978, a national plan was formulated in accordance with the Alma declaration for a nationwide expansion. This Alma declaration argues Nwankwo (2006) includes:

(i) 30\% immunization coverage for children less than 2 years by the year 1990

(ii) Improvement in coverage of fully immunized children

(iii) Improvement of the cold chain and possible local vaccine production

(iv) Establishment of surveillance system for the target disease.

(v) Development of monitoring and evaluation system of EPI

(vi) Integration of EPI and ORT. It is pertinent to remark that Expanded Programme on Immunization is a global policy, which was later Nigerianised and rechristened "National Programme on Immunization (NPI)".

\subsection{Statement of Problem}

For decades now, UNICEF under the auspices of United Nations Organisation has been making effort to help emerging states in many areas including health related issues. Nigeria is one of the new states that has been benefiting from this untied aid, which ranges from malarial control, guinea worm control, river blindness and expanded program on immunization/National Programme on Immunization (EPI-NPI) which is the policy this study sets out to investigate. A cursory look at the immunization policy in Nigeria especially Enugu State indicates that the programme has not made the intended impact expected of it. There is still high infant mortality especially in rural communities of Enugu State. The imbroglio is also common in other rural communities in Nigeria. It is believed, that the programme is perceived by most rural dwellers as contradicting their culture and religious beliefs. Some associate the programme with myths (Ugbo, 2014).

There is also the case of inadequate public enlightment campaign on immunization in the State, high immunization dropout rates, cultural ethos, and poor laboratory monitoring and programme evaluation surveys. According to Ugbo (2014) the immunization survey in Enugu State revealed a negligible impact on the incidence of the target diseases. Reasons for this among others include inertia in the implementation of the programme, inadequate facilities and equipment, an access to vaccination, poor community awareness and participation. A cursory look at the implementation problems indicates that the government structure has not captured this policy properly. It is also important to note that cerebrospinal meningitis (CSM) is administered at twelve (12) months according to the NPI schedule but in Enugu State, it is not administered routinely. The same case with malaria related immunization. Cases abound when malaria drugs like "Coatem" produced by Novatis sponsored by Donor agencies are sold freely in the open market. Most of the vaccines are administered only where there is reported cases of epidemic. There is the case of poor disease surveillance. In view of the perceived problems, the following research questions therefore become imperative: 
(a) To what extent has the NPI awareness creation been able to reach the target population?

(b) Is there a significant relationship between health workers sensitization and client's completion of the immunization schedule as prescribed by NPI?

\subsection{Objectives of the Study}

The specific objectives of the sturdy are:

(1) To find out whether the level of awareness campaign by Government is sufficient to impact on NPI access in Enugu State.

(2) To investigate whether the immunization schedule is completed in Enugu State.

(3) To identify other hidden extraneous variables that militate against the smooth implementation of the EPI program in Enugu State.

\subsection{Hypotheses}

(1) There is correlation between immunization awareness campaign and NPI access in Enugu State

(2) High infant mortality is being recorded in most communities in Enugu State because immunization schedule is not completed.

\section{Literature Review}

To understand fully the framework of immunization as a component of health policy and its eventual implementation, it is very pertinent to review the historical background of health care (medical) system in Nigeria. The evolution of primary health care (PHC) in Nigeria argues Oji (2014) is multi-faceted. It could be traced to three convenient periods Pre-colonial, colonial era and post-colonial era (Egu, 1992).

Health care in the pre-colonial era comprised traditional care continuum, which antedated the colonial and post-colonial periods. The National policy on EPI did not happen in a vacuum. In Nigeria, the traditional medical practices in most areas of the Country existed long before the contact and subsequent influence of the colonial agents. Example includes: Herbalists, traditional birth attendants (TBAS), traditional surgeons etc (Oji, 2014). While these practices in different societies are not in doubt, what might be called to question is whether they were systematic, that is 'organized'. It will be evident in subsequent discussion that even modern health was almost piggy-backed in the national development plan.

Health care services were initially 'unorganized' and therefore not systematic with reference to public policy. In this respect, the early modern health services in Nigeria can be described as having functioned as a 'non-system'.

Public policy argues Chukwuemeka (2017) generally engenders global directives or framework on the main lines of action to be followed (Dror, 1973). Both colonial and post-colonial health services were provided without framework or planning, although social services, inclusive of health, formed portions of successive National Development Plans. Health was almost 'piggy-backed' on the National Development Plans, and until relatively of 
recent, there was no formal National Health Policy in Nigeria. In 1996 there was adoption and lunching of the Nigerian National Health Policy, which aimed at achieving a level of health that will enable the individuals have communities to live economically have productive life. It is pertinent to note that before 1986, there was no formal health policy in Nigeria.

The health care in the colonial era spanned the period from the period of colonial rule in 1960, when Nigeria became independent. This era was the period when the first attempt at planning health services development in Nigeria (Egwu, 1996). This effort was also part of exercise which produced the overall ten-year development plans (1946-1956), covering all aspects of governmental activities in the Country (Sorungbe, 1990).

The post-colonial era was the period when colonial services became Regional Medical Services after independence i.e. from 1960 (Egwu, 1996). .Regionalization continued until the creation of new states from 1967-1975, resulting in the formation of state health services ministries. The second National Development Plans (1970-1974) recognizes significant flaws in the colonial development plan, with respect to its health component, there were shortages of work force and infrastructures. The desirability to increase appreciably the stock of doctors and paramedical personnel and their distribution, were clearly pointed out in the second National Development Plan (Egwu, 1996). The Third National Development Plan (1975-1980) was characterized by deliberate attempt to draw up a comprehensive national health policy dealing with health manpower development, provision of health care services based on the Basic Health Services Scheme (BHSS), disease control, efficient utilization of resources, medical research, health planning and management (Sorunghe, 1990).

The fourth National Development Plan (1981-1985) was a period when the health sector was indented to pursue the goal of providing a comprehensive health care system which would offer primitive, protective, restorative and rehabilitative services to an increasing proportion of the populace. The comprehensive health care system was termed "Health Policy". The health policy envisaged three levels of care namely: Primary (Basic) Health Care (PHC), Secondary Health Care and Tertiary Health Care. Functionally, these three levels of care were to offer the following services argues Egwu (1996).

The Primary Health Care level was to provide health care services in the health centers, Clinics and Out Patients Department (OPD) of hospitals in rural, sub-rural and urban centers. The secondary health care level was to provide health care services partly in hospitals. It was also to provide referral services to support the basic and specialist services for individuals.

The Tertiary Health Care level was to be provided in the specialist and teaching hospitals institutions to support the basic and secondary levels of care. Out of these three care systems discussed, our major area of focus is immunization as a component of primary health care system as stated in the health policy document of 1996.

\subsection{National Program on Immunization as a Health Policy in Nigeria}

Health policy is governmental action and programs of action towards solving the societal health problems. Immunization, which is a process by which immunity is being built by 
individuals against infections, may be acquired naturally or artificially. A natural acquired immunization is achieved through the child's mother while an artificially acquired immunity involves achieving immunity through the use of vaccines - immunization. Immunization is the most powerful cost-effective means of preventing some of the deadly diseases of childhood as well as being one of the eight components of primary health care. A child who is immune to a disease is protected against the disease by means of antibodies. The antibody can be passive, that is given to the child ready-made as in serum or from the mother to the child through the placenta (Chinawa, 2014).

The prevention of diseases by immunization, conventional public health measures is today the best known, practical, low cost, community based way of protecting children against the major killer childhood diseases. Primary Health Care (PHC) according to World Health Organization (WHO) has become the accepted key to reaching the social target of attainment by all people of the world by the year 2020, of a level of health that will permit them to lead a socially and economically productive life (Ayodele, 2018).

United Nations Children's Fund (UNICEF), in a world view of the existing high infant and child mortality rates in developing countries, has formulated a package of priority activities, which are synergistic, cost effective and simple. They are growth monitoring, oral, rehydration, breast feeding, immunization, family spacing, female education and food supplementation (GABI -FFF). This combination of activities has been publicized and survival and development resolution, which will receive political support and help change the world's response to the plight of children from one of resignation to one of refusal to allow the present state to continue. The daily unnecessary loss of forty thousand children from measles, peruses and tuberculosis must be placed on people's consciences and nations must make accessible to all parents the simple intentions that prevent not only death of their infants but also a heave burden of morbidity, retarded development as disability.

Following the success of small pox vaccination, the World Health Organization (WHO) in 1974 launched a series of country-based initiatives entitled 'Expanded Program on Immunization (EPI). The long term objectives are: (i) Reducing the morbidity and mortality of six childhood diseases: diphtheria, pertussis, tetanus (neonatal tetanus) poliomyelitis, measles, and tuberculosis. (ii) Immunizing all children by the year 1990 (Oji 2014).

This was to be vertical program within the primary health services of each country. Immunization however, developed slowly in the third world. Introduced into the general Health Services for mothers and children as a routine measure, coverage was minimal. In 1974 , it was estimated that only five percent $(5 \%)$ of the total childhood population of the world had been covered by a complete schedule of primary immunization. This was despite measles causing the deaths of nearly one million $(1,000,000)$ children, pertussis the death of half a million $(500,000)$ children, tetanus the death of nearly one million, neonates and poliomyelitis, the crippling of up to one million children annually.

The Expanded Program on Immunization (EPI) was first launched in Nigeria in 1978 and re-lunched in 1984 and was rechristened National Programme on Immunization NPI. The name NPI indicates that EPI has been adopted and Nigerianized as a health policy. 
Poor management of vaccines, inadequate public enlightment, poor laboratory monitoring and evaluation of the program were identified as the constraining factors affecting the effectiveness of the program from its inception, the importance of community participation in ensuring the success of NPI was recognized and actively sought. To achieve universal access that is sustainable, a new strategy of social mobilization and communication is required to reach the hard-to-reach places. It is possible to make parents (especially those in obscure areas) aware of the importance of immunization for their children survival and development.

There is also a dire need for mobilization of national political will and involvement of all sections of the health bureaucracy and of other sectors. So far, the access to NPI has not been very much encouraging in Nigeria, especially in rural communities of Enugu State despite the government drastic measures to ensure that EPI is made accessible to all. Available records show that in the rural communities especially in Enugu State, many children do not take full dose of the immunization. Many also do not bring their children for immunization at all (Chinawa, 2014).The complete scheduled doses are presented in tables 1 and 2 below:

Table 1. The approved immunization schedule by National Program on Immunization (NPI in the at birth to 18 months

\begin{tabular}{|c|c|c|c|}
\hline Targeted age group & Name of vaccine & Dosage & $\begin{array}{c}\text { Route of } \\
\text { Administration (site) }\end{array}$ \\
\hline \multirow{3}{*}{ At birth } & BCG Sabin & & \multirow{3}{*}{ Intra-muscular oral } \\
\hline & HBV & $0.052-3$ drops & \\
\hline & OPV 0 & & \\
\hline \multirow{3}{*}{6 weeks } & Penta 1 & \multirow{3}{*}{$0.5 \mathrm{ml}$} & \multirow{3}{*}{ Intra-muscular oral } \\
\hline & PCV 1 & & \\
\hline & $\mathrm{OPV}_{1}$ & & \\
\hline \multirow{4}{*}{10 weeks } & Penta 2 & & \multirow{4}{*}{ Intra-muscular oral } \\
\hline & Penta 3 & $0.5 \mathrm{ml}$ & \\
\hline & $\mathrm{PC} \mathrm{V}_{2}$ & 2-3 drops & \\
\hline & $\mathrm{OPV}_{2}$ & & \\
\hline 14 weeks & $\mathrm{DPT}_{3}$ & \multirow{2}{*}{$0.5 \mathrm{ml} \mathrm{2-3}$ days } & \multirow{2}{*}{ Intra-muscular oral } \\
\hline & $\mathrm{OPV}_{3}$ & & \\
\hline 6 months & Vitamin A & \multirow{6}{*}{$\begin{array}{c}3 \text { drops } \\
0.5 \mathrm{ml} \\
0.5 \mathrm{ml}\end{array}$} & \multirow{6}{*}{$\begin{array}{c}\text { Oral } \\
\text { Oral sub-cutaneous } \\
\text { Intra-muscular }\end{array}$} \\
\hline 9 months & Measles 1 & & \\
\hline 9 months & Yellow fever & & \\
\hline 12 Months & Vitamin A & & \\
\hline 18 months & Vitamin A & & \\
\hline 18 months & Measles 2 & & \\
\hline
\end{tabular}

Source: Aninri LGA Health Dept Immunization Record 
Table 2. Schedule for Neonatal Tetanus

$1^{\text {st }}$ dose $\quad-1^{\text {st }}$ contact

$2^{\text {nd }}$ dose $\quad-\quad 4$ weeks later

$3^{\text {rd }}$ dose $\quad-\quad 6$ months later

$4^{\text {th }}$ dose $\quad-1$ year later

$5^{\text {th }}$ dose $\quad-\quad 1$ year (For life coverage)

Source: Aninri LGA Health Dept immunization record

\subsection{Immunization and Public Policy: The Nexus}

Immunization of children against the killer diseases has proven effective in reducing the morbidity and mortality from those diseases. For this reason, World Health Organisation (WHO) recommends that all children receive one dose of bacilli calmette-gueria vaccine, three doses of diphthjeria-tatanus pertussis vaccine, vaccine (DPT), three doses of either oral polio vaccine or inactivated polio vaccine, three doses of hepatitis $B$ vaccine and one dose of a measles virus-containing vaccine, either anti-measles alone or in combination with other antigens (Chinawa, 2017). It also recommends three doses of vaccine against infection with Haemophilus influenza type B. To boost immune at older ages, additional immunization are recommended for healthcare workers, travelers, high-risk groups and people in areas where the risk of specific vaccine-preventable diseases is high.

The policy is well intended but unfortunately, the impact is still very low after many years of the programme. It is pertinent to ask whether the governance is proactive in the sustenance of this all important policy?

\subsection{Why Public Policy May Not Make the Intended Impact}

Policy evaluation often indicates that policies do not achieve the goals they were intended to have. For instance the policy of NPI in the rural communities in Enugu State has not been able to stamp out child killer diseases due to the fact that there are multiplicity of factors like immunization drop outs, cultural and religious beliefs etc.

Therefore a number of factors may impede the attainment of policy goals argues Chukwuemeka (2013). They are:

(1) Multiplicity of causes of problem

Policy problems are quite often caused by multiple factors, for instance, negative practices of public health workers like sale of vaccines to the open market, lack of cordial relationship with clients and so many other negative practices that make mother dread vaccines could impair the implementation of NPI. Therefore any policy made to foster the implementation of NPI, should take into consideration those intervening variables.

(2) Public Policy has incompatible goals

When policies are made without taking into consideration incompatible, goals it tends to affect the impact of the policy. For instance, the Nigerian government adopted the policy of 
health for all by the year 2000 and promotion of free medication for all, and at the same time drugs and vaccines are always out of stock in public hospitals. Definitely, the people will resort to patronize quacks and traditional medicines, while the impecunious clients would sit at home and hope on faith.

(3) Resources

When a good policy is formulated and fund is not made adequately available, such policy stands the chances of failing. For instance most rural development policies and programmes in Nigeria failed due to resources (fiscal, human and material).

(4) Cost of problem solution

Most public problems are so complex that the cost of ameliorating the problem may be higher than the benefit derivable of the policy.

(5) Emergence of new problem

Sometimes in the course of policy implementation, a new problem may arise which automatically diverts attention from the existing problem. For instance in the course of giving BCG sabin the vaccine given at birth and it was discovered that in every 10 children that received it got deformed. Attention will be diverted and efforts would be made to formulate policy or programme to address the emerging tragedy.

(6) Insolubility of some problems

Some policy may defy conclusive solution. In this case, to eliminate them may prove futile. For instance, "health for all programme" may be difficult to thrive in some Islamic communities where people perceive immunization as a taboos.

\section{Methodology}

The study was carried out in six Local Government Areas of Enugu State namely:

Aninri, Awgu, Oji River, Nkanu West, Udenu, and Igbo Etiti. The study population consisted of management staff of the Health Department in each of the six LGAs. Seventy one people were randomly selected from Aninri, while sixty six (66) people were selected from the rest of the five LGAs. Those selected were middle age mothers. Also some staff of the Local Government Health Department were purposively selected from the staff nominal roll. Most of the staff sampled belonged to the policy formulation and implementation levels. A few health workers of Enugu State Ministry of Health were also interviewed. Focus group discussion was also used to elicit information from most rural dwellers who have aversion for immunization. A good number of rural women in the study areas were also interviewed.

Data for the study were collected from both primary and secondary sources. The primary data were collected using structured questionnaire administered to staff of the Health Departments in the selected Local Government Council of study. Information sourced included: knowledge of NPI, National Health policies, drug resistance, health policy implementation, health development, commercialization of immunization vaccines, questions on fake, counterfeit and expired drugs, list of sanctioned public health workers, immunization dropout rate, cold chain facilities, constraints that impinge on the effective implementation of NEPI etc. The 
rural and super rural women were asked questions like "why did you choose not to take your children for immunization?"

The questionnaire was administered by the researchers and research assistants across the local governments selected for the study. A combination of some form of participant observation especially where the researchers were allowed to attend seminars organized by the sampled organizations was also employed. The secondary data were collected from relevant WHO, UNICEF, DFID, MOH Enugu publications, books, journals, bulletins, periodicals, monographs, reports and internet sources.

The tools used for data analysis were correlation coefficient and chi-square.

Table 3. Distribution and Return of Questionnaire

\begin{tabular}{cccc}
\hline LG & $\begin{array}{c}\text { Questionnaire } \\
\text { Distributed }\end{array}$ & $\begin{array}{c}\text { Questionnaire } \\
\text { Returned }\end{array}$ & $\begin{array}{c}\text { Questionnaire Not } \\
\text { returned }\end{array}$ \\
\hline Aninri & 66 & 59 & 07 \\
Awgu & 66 & 63 & 03 \\
Oji River & 66 & 60 & 06 \\
Nkanu West & 71 & 68 & 03 \\
Udenu & 66 & 56 & 10 \\
Igbo Etiti & 66 & 54 & 12 \\
Total & 401 & 360 & 41 \\
\hline
\end{tabular}

Source: Field Survey, 2018

Percentage of questionnaire returned: $\mathrm{QR}=\mathrm{TQD}-\mathrm{QNR} \quad \mathrm{x} 100$

Where $\mathrm{QR}=$ Questionnaire returned

TQD = Total questionnaire distributed

QNR = Questionnaire not returned

From the above:

$\mathrm{QR}=\mathrm{TQD}-\mathrm{QNR} \times 100$

TQD $=401-42 \times 100$

$=360 \times 100$

$401=89.8 \%$




\section{Macrothink}

Table 3 above showed high rate of questionnaire returned. In the six local government areas covered, sixty -six questionnaire was distributed in Aninri and fifty- nine returned. Thus, a negligible number of seven questionnaire were not returned. Same number were distributed to the respondents in Awgu LGA, but three were not returned. Sixty- six, and seventy- one questionnaire were administered to respondents in Oji River and Awgu LGAs respectively. Questionnaire not returned were six and three respectively. Sixty -six questionnaire was administered to respondents in Udenu and Igbo Etiti LGAs, only ten and twelve people were not able to return theirs. Thus, out of total questionnaire of 401 distributed, 360 were returned, given a good percentage $(89.8 \%)$ of questionnaire return rate. This was further expressed in the formula

$\mathrm{QR}=\underline{\mathrm{TQD}-\mathrm{QNR} \times 100}$

TQD

Test of hypotheses 1: There is correlation between immunization awareness campaign and EPI access in Enugu State.

Table 4. Level of awareness of NPI among mothers in community health centers studied for five days

\begin{tabular}{ccc}
\hline Day & $\begin{array}{c}\text { No. of mothers who came for } \\
\text { immunization }(\mathrm{X})\end{array}$ & $\begin{array}{c}\text { Number of mothers who came because they } \\
\text { were sensitized (Y) }\end{array}$ \\
\hline 1 & 6 & 2 \\
2 & 8 & 2 \\
3 & 10 & 1 \\
4 & 7 & 1 \\
5 & 10 & 1 \\
Total & 41 & 07 \\
\hline
\end{tabular}

Source: Field survey, 2018

Table 4 above revealed that out of forty- one mothers that presented their children for immunization, only seven accepted that they were sensitized. The study was carried out for five days consecutively. Out of six mothers who came to immunize their children on day one, only two agreed that they were sensitized. Out of eight mothers that came on day two only two agreed that they were sensitized. On days three, four and five, twenty - seven mothers came to immunize their children, out of this number only three mothers agreed that they were sensitized. The table was further subjected to correlational test as could be seen in table 5 below. 
Table 5. Correlation coefficient table

\begin{tabular}{ccccccc}
\hline $\mathrm{X}$ & $\mathrm{Y}$ & $\mathrm{X}-\overline{\mathrm{X}}$ & $\mathrm{Y}-\overline{\mathrm{Y}}$ & $(\mathrm{X}-\overline{\mathrm{X}})^{2}$ & $(\overline{\mathrm{Y}}-\mathrm{Y})^{2}$ & $(\mathrm{X}-\overline{\mathrm{X}})(\mathrm{Y}-\overline{\mathrm{Y}})$ \\
\hline 6 & 2 & $-2,2$ & 0.6 & 4.84 & 0.36 & 1.32 \\
8 & 2 & -0.2 & 0.6 & 0.44 & & 0.12 \\
10 & 1 & 1.8 & -0.4 & 3.24 & 0.16 & 0.72 \\
7 & 1 & -1.2 & -0.4 & 1.44 & 0.16 & 0.48 \\
10 & 1 & 1.8 & -0.4 & 3.24 & 0.16 & 0.72 \\
41 & 7 & 0 & 0 & 13.2 & 1.2 & 3.36 \\
\hline
\end{tabular}

Source: Compiled from table 3

$$
\begin{aligned}
\mathrm{X} & =8.2 \\
\mathrm{Y} & =1.4 \\
\mathrm{r} & =\frac{\sum(\overline{\mathrm{X}-\mathrm{X}})(\overline{\mathrm{Y}}-\mathrm{Y})}{\sqrt{\bar{\Sigma}(\mathrm{X}-\mathrm{X})^{2}} \Sigma(\mathrm{Y}-\mathrm{Y})^{2}} \\
\mathrm{r} & =\frac{3.36}{(13.2)(1.2)} \\
\mathrm{r} & =\frac{3.36}{(3.36)(1-09)} \\
\mathrm{r} & =\frac{3.36}{3.96} \\
\mathrm{r} & =+0.84
\end{aligned}
$$

From the above analysis, 0.84 indicates that there is a strong positive correlation between NPI awareness and number of mothers who bring their children for full immunization..

Hypothesis 2: High infant mortality is recorded in most communities in Enugu State because immunization schedule is not completed resulting to high drop out rate.

Table 6. Respondents' opinion on completion of the immunization schedule

Question: Did you complete the immunization schedule during your last birth?

\begin{tabular}{cccc}
\hline LG & Yes & No & Total \\
\hline Aninri & $30(34.2)$ & $29(24.7)$ & 59 \\
Awgu & $29(36.5)$ & $34(26.4)$ & 63 \\
Oji River & $30(34.8)$ & $30(25.1)$ & 60 \\
Nkanu West & $40(39.4)$ & $28(28.5)$ & 68 \\
\hline
\end{tabular}




$\begin{array}{cccc}\text { Udenu } & 43(32.5) & 13(23.4) & 56 \\ \text { Igbo Etiti } & 37(31.3) & 17(22.6) & 54 \\ \text { Total } & 209 & 151 & 360\end{array}$

Source: Field Survey (2018)

Table 6 above presented the immunization schedule completion rate. Out of -fifty-nine respondents in Aninri LGA, thirty accepted that they completed the immunization schedule, while twenty- nine opined that they did not. Out of sixty-three respondents in Awgu LGA, twenty- nine claimed that they completed the immunization schedule while thirty- four did not. Out of sixty and sixty- eight respondents in Oji River and Nkanu LGAs, forty and forty -three respondents claimed that they completed the immunization schedule as against thirty and twenty- eight respondents who claimed that they did not complete the schedule. Out of fifty- six and fifty- four respondents in Udenu and Igbo -Etiti LGAs, forty- three and thirtyseven claimed that they completed the immunization schedule as against thirteen and seventeen respondents who opined that they did not complete the circle. The table was further subjected to Chi-square non-parametric test as per Table 7.

Table 7. Chi square test of independence for observed and expected frequencies.

\begin{tabular}{cccccc}
\hline & 0 & $\mathrm{E}$ & $0-\mathrm{E}$ & $(\mathrm{O}-\mathrm{E})^{2}$ & $\frac{(\mathrm{O}-\mathrm{E})^{2}}{\mathrm{E}}$ \\
\hline \multirow{4}{*}{ Yes } & 30 & 34.2 & -4.2 & 17.64 & 0.51 \\
& 29 & 36.5 & -7.5 & 56.25 & 1.54 \\
& 30 & 34.8 & -4.8 & 23.04 & 0.66 \\
& 40 & 39.4 & 0.6 & 0.36 & 0.00 \\
& 43 & 32.5 & 10.5 & 110.25 & 3.39 \\
& 37 & 31.3 & 5.7 & 32.49 & 1.03 \\
\hline
\end{tabular}

\begin{tabular}{llllll}
\hline No & 29 & 24.7 & 4.3 & 18.49 & 0.74 \\
& 34 & 26.4 & 7.6 & 57.76 & 2.18 \\
30 & 25.1 & 4.9 & 24.01 & 0.95 \\
28 & 28.5 & -0.5 & 0.25 & 0.00 \\
13 & 23.4 & -10.4 & 10.16 & 4.62 \\
& 17 & 22.6 & -5.6 & 31.36 & 1.38 \\
& 160 & 359.1 & 0 & 480.06 & 17.00 \\
\hline
\end{tabular}

Source: Field Survey, (2018)

Decision Rule

Accept Ho if tabulated value (T.V)

$\geq$ Calculated value $(\mathrm{CV})$ 
Reject Ho if T.V. $\leq$ C.V

Table 6 analyzed

At 0.05 significance level, degree of freedom $(\mathrm{df})=(\mathrm{r}-1(\mathrm{c}-1)$

$\mathrm{Df}=(2-1)(6-1)=5 \times 1 \times 5$

$\mathrm{TV}=11.070$

$\mathrm{CV}=17.00$

\section{Decision}

Since TV is less than CV at 5\% significance level, we accept the Ho that High infant mortality recorded in Enugu State is not because mothers did not complete the immunization schedule. The implication is that once a mother has come to take the first dose of immunization, she tries to keep faith to complete the schedule. We went further to interview many of them. Only a few agreed that they forgot to complete the schedule because of family pressure.

\section{Findings and Discussions}

The study revealed that the health policies in Nigeria, especially that of National Program on Immunization has not achieved the intended aim, this is largely due to the insufficient awareness and sensitization of mothers especially the illiterate ones. The study further revealed that there is a clear aversion of mothers to embrace NPI program especially in rural communities of Enugu State. It was also revealed that the ratio of public health officer to clients has not been achieved. Thus, public health field officers per 100,000 people were fewer than 30. The effectiveness of immunization had dropped from $40 \%$ in 1990 to $30 \%$ from 1996-2017 due to poor awareness creation and sensitization exercise (Uwakwe, 2018). Other factors that were discovered to impinge upon effectiveness of immunization programme in Enugu State includes high immunization dropout rates, lack of adequate training for public health field officers. The focus group discussion revealed that fear of unfounded myths about immunization by some illiterate mothers impede the willingness to embrace immunization and also to complete the circle.

The Federal Government of Nigeria document on immunization policy (2014), revealed that $80 \%$ of child killer disease cases are inadequately managed at community level largely due to facilities and inability to differentiate between counterfeit and genuine drugs. The assumption was further highlighted by prominent health workers interviewed.

We also gathered from the focus group discussion that the National Programme on Immunization (NPI) suffers recurrent setbacks due to many factors including ethnicity, religious and cultural beliefs. Unfounded myths of illiterate mothers. Other reasons adduced for the low value varies from non-acceptance of immunization in most rural communities in Enugu State because of religio-cultural beliefs. Other reasons for low coverage is resistance from parents. It was revealed that when parents resist vaccination, it is because they want to protect their children from harm. In 2014, most rural dwellers in Aninri Local Government Area boycotted a WHO polio vaccination campaign, claiming that the vaccine can cause 
sterility and acquired immune deficiency syndrome (Jegede, 2017).

Chinawa (2017) argues that the high immunization dropout rates in Enugu State is essentially the function of religious and cultural beliefs. He further contents that out of 972 children who are within 1 year who are residents in the Awgu Health Centre in 2013, 63\% (613/972) were immunized for DPT3 (diphtheria, pertussis and tetanus) while 63.7\% (619/972) were immunized DPT1. This gives an overall dropout rates and percentage of 6 and $1 \%(6 / 613)$ respectively. Immunization coverage for 2012 was also stratified into intervals of 4 months from January to April 2012, 168 children received DPT1 while 166 received DPT3. This gives a dropout rate and percent of 2 and $0.6 \%(2 / 166)$ respectively.

He also contends that between May and August 2012, 222 children received DPT1 while 226 received DPT3. Dropout rate and percentage of -4 and $-1.8 \%(-4 / 222)$ were obtained respectively.

The last quarter of the year (September to December 2012) showed that 223 children received DPT1 while 227 received DPT3. This gave dropout rate and percentage of -4 and $-1.8 \%$ $(-4 / 223)$ were obtained respectively.

The average number of children immunized for DPT1 and DPT3 per month is 61.3 and 60.7 respectively. When immunization of DPT1 and DPT3 were compared at 4 months intervals, the dropout rate is not satisfactory.

\section{Recommendations}

In the light of the findings, the following recommendations have become imperative.

(1) Immunization culture should be adopted if any meaningful achievement is to be made with respect to NPI programme implementation. If immunization culture is cultivated, parents will recognize the need to have their children immunized and spontaneously take them to clinics for immunization on schedule.

(2) The cold chain system should be properly followed to ensure efficacy of vaccines. It is also recommended that emphasis in training should be on continuing education and on-the-job training. This will ensure some level of improvement in this regard.

(3) Policy on involvement of private health care providers need to be clarified. This is because a good percentage of new babies are born in these private health institutions

(4) Effective awareness campaign should henceforth be mounted to ensure that information about NPI gets to the nooks and crannies of our rural communities.

(5) Health workers involved in NPI programme should be exposed to training on public relations to enable them handle mothers and children as human beings and not machines. In addition, they should be trained on the handling of vaccines.

(6) A progress report should be sent to the main bodies in charge of immunization program both locally (i.e. NPI) and internationally (i.e. WHO, UNICEF) so that in return, they can send incentives to the health workers involved in the programme.

(7) There should be regular supply of vaccines. In addition, there should be regular power 
supply to maintain the potency of the vaccines in the cold chain.

(8) Mothers should be awarded immunization certificates when they complete the cycle. It will act as a stimulant to those who do not immunize their children and those who drop out.

(9) Potency of drugs should be checked before administration.

(10) Finally, Enugu State should formulate policy to ensure that any immunization dropouts or non-participants do not receive any democracy dividends from the Government.

From the foregoing, the Enugu State Government is advised to formulate policies and programmes to address these recommendations.

\section{References}

Ayodele, H. K. (2018). Curbing Infant mortality in Nigeria: Which way Nigeria. Journal of Policy and Development Studies, 3(2), 44-70.

Chinawa, J. M. (2017). Immunization Dropout Rates in the Awgu Local Government Area, Enugu State, South East Nigeria. Annals of Medical Health Sciences Research, 1 July-August.

Chukwuemeka, E. O. (2006). Research Methods and Thesis Writing: A Multi-disciplinary Approach. Enugu: HRV Publishers.

Chukwuemeka, E. O. (2013). The Substance of Public Administration in Nigeria (A Compendium). Saarbruken Germany, Lambart Academic Publishing.

Chukwuemeka, E. O. (2017). Counterfeit drugs and malaria control in Nigeria: Policy question. International Journal of Sustainable Development (India), 1(1), 33-50.

Chukwuemeka, E.O. (2009). Impediments to policy implementation in emerging states. Review of Public Administration and Management, 3(1), 49-65.

Colto P. E. (1990). Primary Health Care in developing states. New York: Washers Press.

Dror, A. (1978). Public Policy Making Re-examined. London: Leonard's Hill Books.

Egwu, I. N. (1992). Community based Primary Health Care in Nigeria: Constraints of Biomedical and Cultural Orientations. Lagos: Emore Press.

Eze, T. O. (2016). Obstacles to the implementation of health policy in Nigeria. International Journal of Development Administration, 4(2), 33-50.

Jegede, A. S. (2015). What Led to the Nigerian boycott of the polio vaccination campaign. Annals of Medical Sciences Research, 1 July-August 2016.

Nwankwo, L. A. (2006). Evaluation of Expanded Program on Immunization in Anambra State. Journal of Social Development, 2(3), 90-101.

Oji, W. I. (2014). Effect of malaria scourge on employee service delivery in selected ministries in Enugu State. International Journal of Sociological Studies, 5(2), 100-130. 


\section{Macrothink}

Journal of Public Management Research

ISSN 2377-3294

2019, Vol. 5, No. 1

Sorungbe, A. O. (1990). Disease in children in the tropics. Journal of Health Management, $3(4), 24-32$

Ugbo, O. O. (2017). Strengthening Health Policy in Nigeria: Periscoping selected rural communities in Anambra State. Journal of Social Studies, 1(1), 26-33.

Uwakwe T. S. (2017). Killer diseases - imperatives of immunization. Journal of Social Issues, 2(7), 33-50.

\section{Appendix -Questionnaire}

Please tick (x) where appropriate

(1) Marital status: (a) Married ( ) (b) Single ( ) (c) Separated ( ) (d) Widow

(2) Age: (a) 19-30 years ( b) 31-42 years ( ) (c) 43 years - and above ( )

(3) LGA: (a) Aninri ( ) (b) Awgu ( ) (c) Oji River ( ) (d) Udenu ( ) (e ) Igbo- Etiti ( )

(4) Are you aware of the immunization programme in Enugu State? (a) Yes ( ) (b) No ( )

(5) If yes, what medium of communication did you receive the information? (a) Radio ( ) (b) Television (c) A friend ( ) (d) Health giver ( ) (e) None of the above ( )

(6) Were you able to complete your child's immunization schedule (a) Yes ( ) (b) No ( )

(7) If no why?

(8) Do you think that immunization programme is embraced by all and sundry in your area?

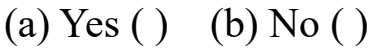

(9) Have you in any way helped to spread the news of immunization (a) Yes ( ) (b) No ( )

(10) If yes, how many people did you convince? (a) 1-20 ( ) (b) 21-40 ( ) (c) 41-60 ( ) (d) 61-80 ( ) ( e) 81 and above ( )

(11) In your opinion, do you think that the immunization programme has helped you (a) Yes ( )

(b) No ( ) (c) No opinion

(12) What is your opinion about public health givers in your area? (a) They are friendly ( )

(b) They are not friendly ( ) (c) They are indifferent (d) They are hostile ( )

\section{Copyright Disclaimer}

Copyright for this article is retained by the author(s), with first publication rights granted to the journal.

This is an open-access article distributed under the terms and conditions of the Creative Commons Attribution license (http://creativecommons.org/licenses/by/3.0/). 